\title{
COMENTÁRIOS
}

\section{Quem Deve Ser o Gerente de Produtos}

\author{
Luiz Fornando Kiehl *
}

1. Introdução. 2. O Conceito da Gerencla de Produtos. 3. Uma Anomalia Dentro da Empresa. 4. Qualidade do Gerente: o $x$ do Problema.

$O$ alcance das funções do gerente de marketing de hoje é muito mais amplo que o de seu predecessor. Sua responsabilidade não se restringe mais apenas à administração de vendas. Na verdade ela começa ao se tomar a decisão quanto aos produtos a serem produzidos. O Total Marketing Concept já penetra em quase todos os setores da emprêsa, incluindo a pesquisa e o desenvolvimento de novos produtos, as embalagens, 0 programa de produção, o contrôle de estoques e 0 estabelecimento de preços. $O$ gerente de marketing moderno é responsável não apenas pelo volume de vendas como também pelo lucro proporcionado por êste volume de vendas.

O crescimento da área do marketing e o contínuo aumento das linhas de produtos sobrecarregaram o gerente de marketing com a administração, coordenação e supervisão de tôdas as atividades envolvidas com a comer-

\footnotetext{
* Bacharel em Administraçăo de Emprèsas pela Escola de Administraçăo de Emprésas de São Paulo da Fundaçăo Getúlio Vargas e Gerente de Pesqulsa de Mercado da Sandoz do Brasil S. A.
}

R. Adm. Emp., Rio de Janelro, cialização de inúmeros produtos ao mesmo tempo. O único meio que éle dispõe para realizar a contento e em tempo suas inúmeras taréfas é a delegação de grande parte de sua responsabilidade a uma equipe competente. $O$ gerente de marketing está deixando de ser o homem de sete instrumentos para ser o maestro de uma orquestra afinada.

A delegação de responsabilidade a especialistas de cada uma das funções do marketing (por exemplo: um de pesquisa de mercado, outro de propaganda, um terceiro de promoçōes, etc.) não resolveria a situação porque o gerente de marketing teria ainda de coordenar tôdas essas atividades. Além disso êle continuaria a ser a pessoa para quem seriam canalizados todos os dados relacionados com todos os produtos. Como os especialistas, seus subordinados entendem dos assuntos relacionados com suas especialidades, mas não possuem uma visão de conjunto do marketing da emprêsa; tôdas as decisões de marketing continuariam a depender de uma única pessoa: o gerente de marketing.

11(1): $\quad 109-114$

Jan./Mar. 1971 
Outra alternativa, mais eficiente, a de clàssificar os produtos em grupos e delegar parte da responsabilidade do marketing de cada um dos grupos para um gerente de produtos.

A grande maioria das atividades do gerente de Marketing, como, por exemplo, análises de situações e problemas, elaboração de planos especificos, elaboração de campanhas de propaganda e promoção, contatos com agéncias de pesquisas de mercado e de propaganda, etc., passam a ser executadas pelos gerentes de produtos, no que se relaciona com os produtos de cada um déles.

Com o gerente de marketing permanecem apenas as funções de supervisão do trabalho de seus gerentes de produtos: avaliaçăo de idélas e sugestōes; escolha de alternativas sugeridas para a solução de problemas e decisão final sôbre a estratégia a ser utilizada.

A gerência de produtos năo é apenas uma maneira de organizar eficazmente o departamento de marketing. Ela é um meio de concentrar a atenção de todos os elementos da emprésa em cada produto especifico. Com o aparecimento do gerente de produtos, o papel do gerente de markeling assume novas dlmensões. Este passa a funcionar em nivel mais elevado do que antes. Embora continue responsável pela gestão global do marketing da emprêsa, êle tende a passar do nivel de planejamento especifico para um nivel mais amplo de planejamento global do marketing da empressa.

Quanto melhores forem os gerentes de produtos mals tempo o gerente de marketing poderá dedicar ao planejamento a médio e longo prazo e mais útil para a emprésa será o seu trabalho.

\section{O Conceito da Gerêncla de Produtos}

A gerência de produtos depende da linha de produtos da emprésa, dos elementos preponderantes de seu marketing-mix, da es- tratégia utilizada com relaçăo aos produtos novos, da posição dos produtos em seu ciclo de vida, da disposição e da capacidade dos altos dirigentes em delegar autoridade e responsabilidade ao gerente de produtos.

Em geral, a gerência de produtos é um conceito através do qual as múltiplas responsabilidades por um só produto ou grupo de produtos se concentram dentro de uma só unidade organizacional.

O gerente de produtos típico é responsável por três funções principais:

- Função Administrativa

- Função Coordenadora

- Função Informativa.

\subsection{A Função Administrativa}

Esta função é composta de três campos principais de responsabilidades:

- Definição de objetivos

- Desenvolvimento de estratégias e planos para atingir os objetivos

- Avaliação dos resultados.

A definiçåo de objetivos é, talvez, a mais dificil das responsabilidades do gerente de produtos. Este é um assunto do qual se deve ocupar a todo momento. Durante 0 ano inteiro o gerente de produtos deve buscar novas oportunidades, analisando as possibilidades a testando novas idéias. E possível que os altos dirigentes da emprésa só se reúnam com éle cada semestre, mas êle não pode esperar até a véspera da reunião para definir metas para o semestre seguinte. As melhores metas são. as que resultam de uma idéia bem amadurecida.

Deve-se estabelecer metas para o volume de vendas a curto e médio prazo, para participação no mercado, posição do produto, margem bruta $e$ margem de contribuição ao lucro. 
o desenvolvimento de estratégias a planos para atingir os objetivos significa a elaboração de um plano de marketing. Este plano de marketing será a base das atividades do gerente de produtos no período seguinte. O plano de marketing inclui um estabelecimento de estratégias com relação ao produto, em sua embalagem, seu preço, a seleção dos canais de distribuição, a propoganda e a promoção de vendas.

A avaliaçăo dos resultados é na realidade um elemento de contróle. A preocupação principal do gerente de produtos quanto a esta parte deve ser a de avaliar em detalhe os resultados de seu grupo de produtos com relação ao volume de vendas, análise de custos promocionais e aumento de vendas, etc. Também deverá preocupar-se em comparar os resultados obtidos pelos seus produtos com os resultados dos produtos concorrentes.

\subsection{A Função Coordenadora}

A chave do sucesso do gerente de produtos está em sua capacidade de desempenhar a contento esta função. Ele deverá coordenar as seguintes atividades:

- Escolha de veículos de propaganda

- Criação e realizaçāo da campanha de propaganda

- Campanhas promocionais, do tipo concursos, distribuição de brindes ou demonstração de produtos

- Criação de novos modelos de embalagens

- Orientação da equipe de vendas com relação a campanhas de descontos, argumentação de vendas, etc.

- Pesquisa de mercado

- Aspectos legais relacionados com seus produtos, como registro de marcas, licenças de fabricação, dizeres obrigatórios na embalagem, etc.

- Fabricação e distribuição, fornecendo previsões de vendas para a fábrica e contro- lando os niveis de estoques $\theta$ de entregas dos produtos.

- O gerente de produtos não realiza pessoalmente nenhuma dessas funçōes. Sua responsabilidade é a de coordenar as atividades dos diversos departamentos da emprêsa e das diversas emprêsas que prestam serviços, em benefício de seus produtos. $O$ gerente de produtos não deve ser um especialista em nenhuma dessas atividades. Ele deve ser, isto sim, um especialista em seu grupo de produtos. Ele não será um especialista em pesquisas de mercado, por exemplo. Ele deve ser um especialista do produto $x$ e do produto $y$, que entende um pouco de propaganda, um pouco de pesquisas de mercado, um pouco de embalagens, um pouco de vendas, etc. Com relação a atividades o gerente de produtos deve ser um generalista. Com relação a seus produtos, deve ser um especialista.

\subsection{A Função Informativa}

Esta função significa que o gerente de produtos deve dispor de informações completas e exatas sóbre seus produtos, não apenas para exercer com sucesso suas funções, como também para funcionar como um ver-

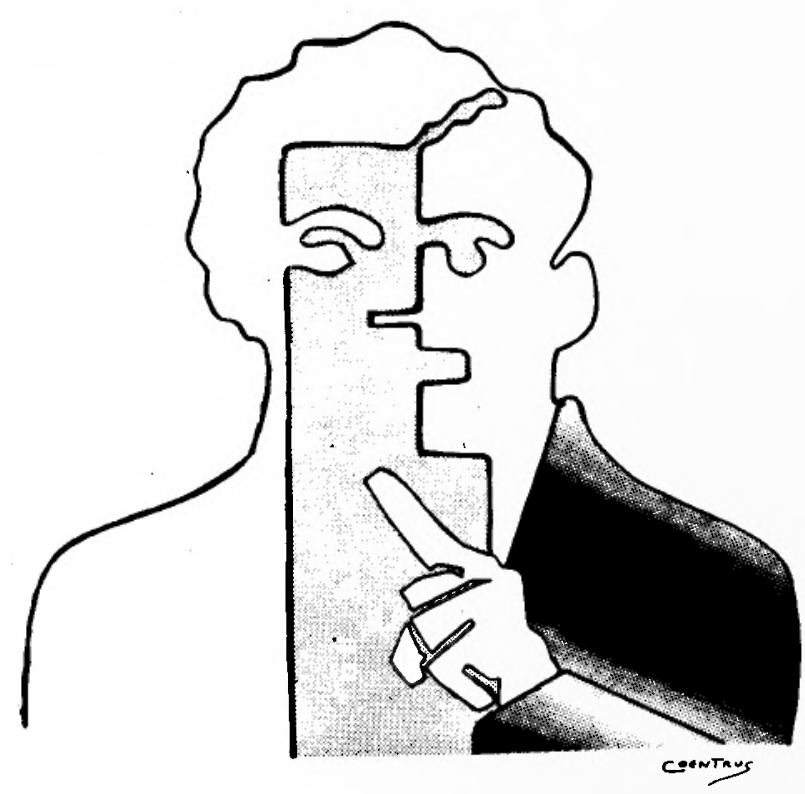


dadeiro centro de informações sôbre seus produtos dentro da emprêsa.

Não há outra pessoa na emprêsa, cujos conhecimentos globais sôbre um produto determinado sejam maiores do que os do gerente de produtos. Assim sendo, êle deve servir como fonte de informação para o departamento de vendas, para os executivos superiores e para o pessoal de todos os niveis dentro da emprésa. O departamento de vendas pode e deve saber mais que o gerente de produtos sôbre alguns detalhes de vendas realizadas e 0 departamento de produção deve saber mais do que êle sôbre a fórmula do produto. Entretanto, o gerente de produtos deve saber o suficiente sôbre todos êsses aspectos de seus produtos para servir como a principal fonte de informação dentro da emprêsa.

\section{Uma Anomalia Dentro da Emprêsa}

Ao se planejar uma organização é quase instintivo atribuir-se uma responsabilidade definida a cada cargo, definindo-se o grau de autoridade necessário para cumprir essa responsabilidade.

O cargo de gerente de produtos é uma das raras exceções a esta regra geral.

o gerente de produtos chega a ser uma anomalia dentro da organização, porque tem uma ampla responsabilidade sỏbre o êxito dos produtos a seu cargo, mas dispõe de uma autoridade muito limitada.

O gerente de produtos não tem autoridade de linha sỏbre ninguém. Não tem o direito nem o dever de dar ordens a ninguém. Ele é um planejador, investigador, analisador, coordenador e fonte de informaçōes, mas não manda em ninguém. $O$ gerente de produtos faz recomendações, mas não toma decisões. Apesar disso êle está intimamente envolvido no processo de tomada de decisões, pois a base das decisões são as suas recomendações e êle tem a mesma responsabilidade pelos resultados como se tivesse tomado as decisões.
Esta situação estranha torna-se prática por vários fatôres.

Primeiro, porque o bom gerente de produtos vai conquistando, aos poucos, o respeito dos executivos através da sabedoria de suas recomendações. Com o correr do tempo o gerente de produtos vai criando uma autoridade implícita baseada na qualidade de seus conhecimentos e sugestōes.

Segundo, porque muitas emprêsas estāo passando a delegar autoridade aos seus gerentes de produtos para tomar decisões dentro do plano de marketing prèviamente aprovado pela diretoria.

E, terceiro, porque o simples fato do gerente de produtos participar indiretamente de tôdas as decisóes relacionadas com seus produtos é algo que o torna uma pessoa, cujas opinióes devem ser ouvidas pelos executivos.

Em algumas emprêsas, êste aspecto particular (de que o gerente de produtos tem responsabilidade, mas não tem autoridade), está sendo resolvido, fazendo com que êle fique responsável por uma contribuição para o lucro da emprêsa. O gerente de produtos compra o produto pelo custo de fabricação. A diferença entre êste custo e o preço de venda é a margem bruta do produto. Deduzindo-se a margem bruta, tôdas as despesas de marketing e mais um custo fixo para o tempo da equipe de vendas, chega-se ao valor da contribuição ao lucro, também chamado margem de contribuição.

Sob êste sistema o gerente de produtos fica responsável apenas pelos fatôres com os quais pode manejar e controlar. Tendo uma parte da contribuição ao lucro da emprêsa como sua responsabilidade, o gerente de produtos não só procurará manejar os meios de marketing da melhor maneira possivel como também se preocupará com os niveis de estoques, com o contrôle de qualidade, com os custos diretos de produção e com todos os fatôres que the permitam comprar a preço mais baixo os seus produtos ou vendê-los melhor. 


\section{Qualidade do Gerento: o X do Problema}

Para assumir o papel que the cabe, 0 gerente de produtos deve ser capaz de planejar e executar programas de marketing. Exceto pelo fato de sua responsabilidade ser restrita a um pequeno número de produtos, sua funçāo é quase igual à do gerente de marketing. Isso significa que o gerente de produtos não pode ser um trainee. Ele deve saber fazer um plano de marketing, conhecer um pouco de finanças, um pouco de propaganda e um pouco de pesquisas de mercado. Embora não sendo um especialista em promoção, deve saber reconhecer os casos em que vendas e propagandas não bastam e quais as promoçőes indicadas. Ele não precisa ter sido vendedor, mas precisa conhecer os problemas que os vendedores enfrentam.

Como homens dêste naipe são raros e, portanto, caros, muitas emprêsas costumam preencher os cargos de gerente de produtos através de uma das seguintes alternativas:

Alternativa 1: contratam um universitário recém-formado em administração de emprêsas e fazem-no estagiar seis meses no departamento de vendas. Depois promovem-no a assistente de um dos gerentes de produtos. A seguir, dependendo do seu progresso aparente, admitem que o jovem tenha aprendido por osmose e, na primeira oportunidade, transformam-no em gerente de produtos.

Alternativa 2: procuram dentro do departamento de vendas alguém que tenha se destacado como vendedor e como chefe de equipe e promovem-no a gerente de produtos.

As emprésas que adotam a alternativa 2 se esquecem que os requisitos para ser um bom vendedor ou chefe de equipe são muito diferentes dos requisitos para ser um bom gerente de produtos. O homem de vendas está condicionado a problemas de cobertura de cotas, não está acostumado, nem gosta, de atividades relacionadas com a análise e planejamento. O homem de vendas é mais um fazedor de coisas do que um pensador.
As conseqüéncias da adoção dessas duas alternativas habituais são as seguintes:

- O gerente de marketing não pode delegar responsabilidades a seus gerentes de produtos e é obrigado a continuar decidindo tudo;

- achando que o sistema não funciona, criamse cada vez mais cargos de gerentes de produtos, substituindo-se qualidade por quantidade. Pouco a pouco, o departamento de marketing vai-se agigantando $\theta$ tornando-se cada vez menos eficiente.

As emprêsas devem-se compenetrar que é melhor ter três gerentes de produtos ganhando 100 cada um, do que seis ganhando 50 cada um.

Acreditamos que se uma emprêsa não pode, ou nāo quer, contratar fora um gerente de produtos experiente, o melhor caminho a seguir é o seguinte:

a) Contratar um rapaz recém-formado em administração de emprésas.

b) Colocar o futuro gerente de produtos trabalhando dois meses como vendedor. E melhor deixá-lo dois meses trabalhando na rua do que seis meses no escritório de vendas. $E$ dois meses batendo de porta em porta são suficientes para que êle conheça os problemas de vendas.

c) Transferir o futuro gerente de produtos para o departamento de pesquisas de mercado, onde deverá passar mais seis meses fazendo análise de pesquisas e entrevistas com o público consumidor. Com isso, êle estará eritrando em contato direto com o consumidor final dos produtos da emprêsa.

d) Depois, conseguir para o futuro gerente de produtos um estágio de seis meses em agência de propaganda, trabalhando (e não apenas olhando um pouco em cada setor, para que se familiarize com as dificuldades e com a terminologia de todos os aspectos da propaganda, desde a criação do 
anúncio até a sua veiculação, passando pela redação, arte, etc.

e) Em seguida, êle deve permanecer uns dois meses no departamento de promoçőes, sempre fazendo coisas.

f) Só então é que o elemento deve ser promovido a assistente de um dos gerentes de produtos, cargo em que permanecerá até que apareça uma vaga de gerente de produtos.

Desta forma, em cêrca de dois anos - jovem recém-formado estará preparado para essa importante função. Quando assumir uma das gerências de produtos, o rapaz será realmente um pequeno gerente de marketing.

A emprêsa que adotar um programa de treinamento como êsse năo deve esquecer-se de esclarecer minuciosamente o futuro gerente de produtos sôbre tôdas essas etapas $\theta$ sobbre os objetivos do programa. Caso contrário, êle terá a impressão de que a emprêsa o está utilizando como mero quebragalhos com tôdas essas transferências aparentemente sem nexo. O futuro gerente de produtos deve estar consciente de que ésses dois anos são importantes no seu treinamento e que servirão como sólida base de uma brilhante carreira profissional.

\section{Bibliografia}

Ames, B. Charles. Payoff from product management. Harvard businese review, nov./dez. 1963.

Drucker, Peter F. Management's new role. Harvard busjness review, nov./dez. 1969.

Eldrige, Clarence E. The role of the product manager. Printer's Ink, 28 abr. 1967.

Evans, Gordon $H$. The product manager's job. Amerlcan Management Association, 1964.

Luck, David J. Interfaces of a product manager, Journal of marketing, out. 1969.

Luck, David J. \& Nowak, Theodore. Product management, vision unfulfilled. Harvard business revlew, maio/ in. 1965.

Sangent, John R., The totai marketing concept. H. B. Maynard, McGraw-Hill Book Company, 1967.

\section{BONUS DA UNESCO}

Facilidades especiais para importaçరes, sem salda de divisas nacionais.

Livros, revistas, materiais cientificos $\theta$ audiovisuais săo obtidos através dos bônus da UNESCO.

Os bónus são utilizados também para pagamentos de sociedades cientificas $\theta$ culturais, $\theta$ de direitos autorais. Atendem-se pedidos de bónus por correspondencla.

Informaçōes: Prala de Botafogo, 188, Caixa Postai 21.120, Tel.: 266-2856, ZC-05, Rio, GB.

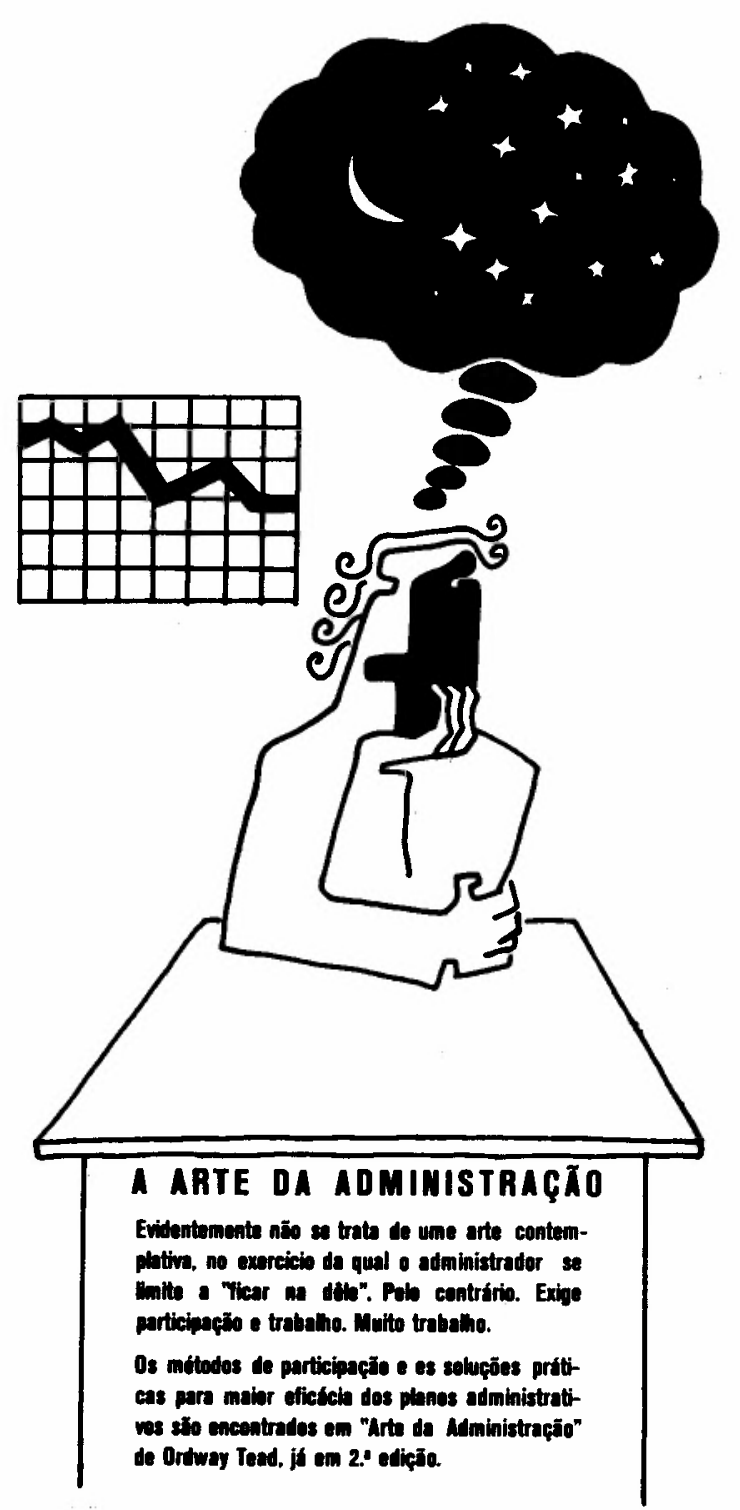

Revista de Administraçāo de Emprésas 